(RESEARCH ARTICLE)

\title{
Predictors of health-promoting behaviour index among employees of different ages across adulthood
}

\author{
Norhilmi Muhammad \\ Faculty of Business and Management, Universiti Sultan Zainal Abidin (UniSZA), Gong Badak Campus, 21300 Kuala Nerus, \\ Terengganu Darul Iman, Malaysia.
}

Publication history: Received on 31 September 2019; revised on 08 November 2019; accepted on 10 November 2019

Article DOI: https://doi.org/10.30574/wjarr.2019.4.1.0072

\begin{abstract}
Employees who have health problems are often less productive at work. Example of health behaviours are considered costly and risky are smoking, excessive alcohol consumption, poor diet, and lack of physical activity. To control costs and improve health, employers seek solutions that will enhance employee health habits and increase the appropriateness or coordination of their health care. Generation X of Malaysia's population is expected to increase to 5.6 million, accounting for $15 \%$ per cent of the total population in Malaysia. Given the size of these generations, their continued health into older age is essential to ensure the stability of Malaysia's workforce and economy. Studies on the influence of social support on the health-promoting of employees who maintain close contact with their family and friends associated themselves with better satisfaction. The aims of this study are to assess the predictors of social support on health-promoting behaviour and to develop a health-promoting behaviour index (HPBi) in a representative population. The study was designed as a questionnaire-based, cross-sectional analysis. A sample of 385 respondents comprising of generation X'ers from Kelantan and Terengganu were involved in this study. This study intends to show the effectiveness of Factor Analysis (FA) and Multiple Linear Regression (MLR) for assessing health-promoting behaviour indicator sources. The method of FA has identified five significant index categories- Excellent, Good, Moderate, Low and poor HPBi were generated from FA.
\end{abstract}

Keywords: Social support; Mind; Mental health; Factor analysis; Multiple linear regression

\section{Introduction}

Change in population size, lower workforce participation, demographic ageing, an increase in life expectancy is some of the critical challenges facing developed countries into the next decades [1]. The changes are predicted to impact on workforce participation and health expenditure, thereby threatening economic growth and reducing the quality of life [2]. Employees who have health problems are often less productive at work. To control costs and improve health, employers seek solutions that improve employee health habits and increase the appropriateness or coordination of their health care. These may also lead to a more productive workforce. Population ageing has become a common concern for social issues around the world. Generation X of Malaysia's population is expected to increase to 5.6 million, accounting for 15\% per cent of the total population in Malaysia [3]. Life expectancy at birth in 2019 remained at 74.5 years, as recorded in 2013, as depicted in Figure 1 below [4]. Besides, life expectancy at the age of 65 years increased. Males who reach the age of 65 years in 2019 is expected to live a further 14.8 years and 17.1 years for females. Thus, males aged 65 years is likely to live until the age of 79.8 years and 82.1 years for females. Given the size of these generations, their continued health into older age is essential to ensure the stability of Malaysia's workforce and economy.

\footnotetext{
${ }^{*}$ Corresponding author

E-mail address: norhilmimd@unisza.edu.my
} 


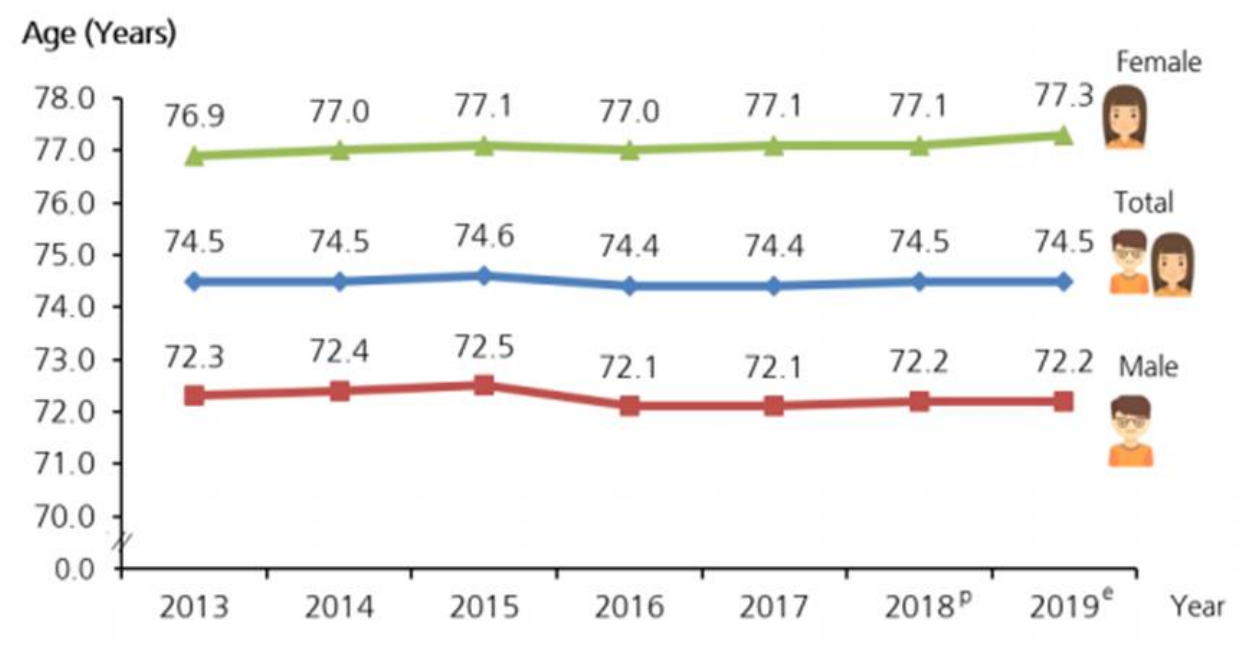

Figure 1 Life Expectancy at Birth, Malaysia, 2013-2019

Sources: (https://www.dosm.gov.my)

As a result of higher numbers of older persons and increased longevity, these changing demographics impact healthcare services and quality of life [5]. Stockert [6] claimed that example of lifestyle changes and that healthy behaviours could benefit the elderly are exercise, diet, smoking and meaningful socialization. By engaging in health-promoting behaviour, individuals can maintain and enhance their well-being and prevent the early onset of disabling health conditions [7]. Adoption of healthy behaviour can slow physical decline from a chronic health problem and even improve general physical and mental wellbeing in older persons [6]. There has been an increase in public awareness of lifestyles and the results of health behaviours for wellness enhancements.

Various behaviours are health-enhancing. However, according to previous literature [8], four health behaviours are considered particularly risky because of their association with a group of chronic diseases: i) smoking; ii) excessive alcohol consumption; iii) poor diet, and iv) lack of physical activity. Identification of how certain factors related to participation in health-promoting activities in older persons is discussed in the literature. It has not been identified what motivates generation $\mathrm{x}$ to practice healthy behaviours. Therefore, it would appear prudent to explore predictor factors of health-promoting behaviour. The purpose of this study is to examine factors influence health-promoting behaviours and to develop index based on health-promoting behaviours items in generation X'ers employees.

Health promotion is defined as various interpretations range from broad to explicit [9]. In addition, health promotion was clarified as health care directed toward high-level wellness through processes that encourage alteration of individuals' personal habits or the environment in which they live [10]. Moreover, health promotion is described in the Health Objectives for the Nation, as any combination of health education and a related organization, environmental and economic interventions designed to promote health [11]. Health-promoting behaviours are essential to attain positive health experience throughout the life span. Examples of these behaviours are a routine exercise, leisure activities, rest, optimal nutrition, and stress-reduction. Asserts that health-promoting behaviour is an expression of the human actualizing tendency that is directed toward optimal well-being, personal fulfilment, and productive living. Pender's Health Promotion Model was chosen as the framework to examine the specific determinants of health-promoting behaviour with generation X'ers. The Health Promotion Model proposes a framework that conceptualized interrelationships of individual characteristics and experiences, and behaviour-specific cognitions and affects, which may influence or predict one's health-promoting behavioural outcome [7]. Some researchers claimed that social support could be measured regarding structural support or functional support [12]. Structural support refers to the extent to which a recipient is connected within a social network, like the number of social ties or how integrated a person is within his or her social network [13]. Family relationships, friends, and membership in clubs and organizations contribute to social integration. Social support may be described as having a family and a network of close friends who provide social and emotional attachment for all physical and emotional needs [14]. This study examined social support and how they influenced health behaviour. 


\section{Material and methods}

\subsection{Material}

This cross-sectional study carried out from July to August 2019 in Terengganu and Kelantan consists of 385 elders from generation X'ers (1960s to1980). The survey questionnaire was distributed based on simple random sampling. For measuring social support, this study adopts the Multidimensional Scale of Perceived Social Support (MSPSS). The MSPSS questionnaire is applied in this study as it is designed to measure the extent to which an individual perceives that family, friends, and significant others fulfil individuals needs for support, information, and feedback, as compared to the PSSS which only covers family and friends [15]. Meanwhile, the Health-Promoting Lifestyle Profile II was used to measure subjects' health-promoting behaviour. The HPLP II is intended to measure health-promoting behaviours, conceptualized as a multidimensional pattern of self-initiated actions and perceptions, which serve to maintain or enhance the level of wellness, self-actualization and fulfilment of the individual [16]. As a result of further development on evaluating components of a healthy lifestyle, the original instrument, HPLP devised in 1987, was revised with the development of the 52-item, HPLP-II. The current HPLP-II consists of six subscales, which are intended to measure healthy lifestyle domains related to physical activity, nutrition, health responsibility, stress management, interpersonal relations, and spiritual growth.

\subsection{Method}

Preliminary source identification of this study was carried out through FA-MLR using XLSTAT 2013 software version 3.1. The primary objective in applying FA analysis is to develop a small number of components to explain the maximum variance possible in the dataset [17]. Prior to analysis, the outlier values were eliminated [18]. FA is applied to identify the underlying dimensions of social support among drug abuse inmates. The FA were executed to infer relationships between variables [19]. Varimax method is used in the FA techniques. The varimax rotation guarantees that every item associated with only one principal component as encompassing a near-zero relationship with the other components [20].

Eigenvalues obtained from varimax rotation are the precursor of the FA. Eigenvalues over than 1 were significant and subsequently varimax factors (VFs), which are the new groups of variables are generated. In this study, the orthogonal varimax rotation method is applied to confirm that the attributes are correlated maximally with one factor and for ease of interpreting the elements. The Anderson-Rubine method is carried in identifying the factor score coefficients in order to confirm that the factor scores are uncorrelated. To determine the social support contribution of the identified sources, the MLR statistical approach was then applied. In the linear regression model, social support values from FA were assigned as independent variables. Meanwhile, HPBi were assigned as dependent variables. The coefficient value $\left(\mathrm{R}^{2}\right)$ in each factor was then used to compute the apportionment of each source to the HPBi.

\section{Results and discussion}

Factor analysis used to identify dominant source categories [21] and the results obtained by varimax rotated factor analysis for HPBi are robust. A factor loading of more than 0.6 and below 0.4 is described as strong and weak respectively. While a loading of between 0.4 and 0.6 is described as moderate [22]. The database consists of nine social support variables and the HPBi. The estimation of the factor loadings was carried out for examining the correlations between social support variables and the extracted factors. In this study, the variables with absolute values greater than 0.70 was set as the selection threshold because these values are stable which exhibit moderate to strong loadings on the extracted factors. After varimax rotation, there were two factors with eigenvalues greater than one and they explained approximately $45.89 \%$ (first factor) and 12.85\% (second factor) of the variance respectively.

Table 1 Factor loadings after varimax rotation of the HPBi for the nine sources social support generated by FA

\begin{tabular}{lllllll}
\hline & $\begin{array}{l}\text { SS/ } \\
\text { HPBi }\end{array}$ & $\begin{array}{l}\text { SS/ } \\
\text { Excellent } \\
\text { HPBi }\end{array}$ & $\begin{array}{l}\text { GS/ } \\
\text { Good } \\
\text { HPBi }\end{array}$ & $\begin{array}{l}\text { SS/ } \\
\text { Moderate } \\
\text { HPBi }\end{array}$ & $\begin{array}{l}\text { Low } / \\
\text { HPBi }\end{array}$ & $\begin{array}{l}\text { SS/ } \\
\text { Poor } \\
\text { HPBi }\end{array}$ \\
\cline { 2 - 7 } R $^{2}$ & 385 & 73 & 207 & 84 & 14 & 7 \\
Adjusted R & & 0.043 & 0.075 & 0.043 & 0.053 & 0.509 \\
RMSE & 0.240 & 0.038 & 0.073 & 0.337 & 0.014 & 0.368 \\
\hline
\end{tabular}


The factor loadings after Varimax rotation of the HPBi for the nine sources social support generated by FA are given in Table 1 . In the poor $\mathrm{HPBi}$, factor 1 explained $42.57 \%$ of the total variance and was dominated by the sources are from family. Meanwhile, factor 2 explained $27.32 \%$ of the total variance and originated from friend. This source was classified based on high factor loadings. In the low HPBi, factor 1 explained $26.32 \%$ of the total variance and originated from family. In the excellent HPBi, factor 1 explained $26.48 \%$ of the total variance and originated from family.

After the major sources were identified for the nine social support variables in the study area, the next step was to determine the contribution of each possible source to the total amount of each social support. To determine the contribution of the identified sources, the MLR statistical approach was then applied. In this study, MLR is used to explain the relationship between the source apportionment generated by FA and their correlation to HPB Index values. The values of $\mathrm{R}^{2}$, adjusted $\mathrm{R}^{2}$ and RMSE for Poor HPBi (2 variables) were $0.509,0.369$ and 0.06 respectively. Followed by the values of $R^{2}$, adjusted $R^{2}$ and RMSE for Low HPBi ( 2 variables) were $0.05,0.01$ and 0.06 respectively. Meanwhile, the values of $\mathrm{R}^{2}$, adjusted $\mathrm{R}^{2}$ and RMSE for Moderate HPBi ( 2 variables) were $0.04,0.04$ and 0.07 . Followed by the values of $\mathrm{R}^{2}$, adjusted $\mathrm{R}^{2}$ and RMSE for Good HPBi (2 variables) were $0.07,0.07$ and 0.07 respectively. Lastly, the values of $\mathrm{R}^{2}$, adjusted $\mathrm{R}^{2}$ and RMSE for Excellent HPBi (2 variables) were $0.07,0.07$ and 0.07 respectively. From the above result, the Poor HPBi shows the highest coefficient of determination $\mathrm{R}^{2}(0.509)$ contributed by the two variables. From the finding, poor HPBi has been selected as the best due to the smallest RMSE and the closest $\mathrm{R}^{2}$ value of 1 when compared among tested variables.

Multiple linear regression (MLR) analysis was done to identify the proposed equation to predict the values of the total HPBi. When comparing from six models developed, the R2 values were found to be strong because they were high and significant at p-value $(<0.05)$. The poor HPBi shows the highest R2 by the Original HPB, High, Low, Excellent, Moderate model. In this study, the finding also indicates that the factors from family contribute the most of the total HPBi among older employees and this factors can be categorized as the crucial bases to the organization to tackle the matter. Additionally, it became vibrant that most of the elders reported satisfaction in the social relationships domain, especially those who received support from family members to provide care. Sharing problems with a particular person and help form family appear in all category shows the importance of the factor.

\section{Conclusion}

The current study has implications for society in optimizing adulthood well-being, personal fulfilment, and productive living research. From this study, it can be concluded that the factor of social support and HPBi were successfully studied by applying FA and MLR. To identify the source social support, FA was done. In this study, the sources of variation are expected derived from family, friends and significance others. Finally, for the economy, family relationships and health inequities should be taken into account in health-promotional policies or intervention programs aimed at behavioural change.

\section{Compliance with ethical standards}

\section{Acknowledgments}

There are no acknowledgements to mention.

\section{Disclosure of conflict of interest}

The author declares no conflict of interest.

\section{References}

[1] Buskens E, Vogt TC, Liefbroer AC, Reijneveld, MS, Bultmann U, Henkens KC, and de Rooij SE. (2019). Healthy Ageing: Challenges and Opportunities of Demographic and Societal Transitions. In Older People: Improving Health and Social Care, 9-31.

[2] Shepherd JG. (2019). Management Approach for Population Health Outcomes and Economic Improvement: Appointing Health Services Early Careerists to Rural Communities for Leadership Development. The health care manager, 38(2), 101-108.

[3] The Star Online. (2019). Malaysia's population increased to 32.66m in Q1.

[4] Department of Statistics Malaysia. (2019). Selected demographic indicator Malaysia. 
[5] Harris A and Sharma A. (2018). Estimating the future health and aged care expenditure in Australia with changes in morbidity. PloS one, 13(8), e0201697.

[6] Stockert PA. (2019). The determinants of a health-promoting lifestyle in older adults (Doctoral dissertation).

[7] Pender NJ. (1996). Health promotion in nursing practice. (3rd. Ed.). Stamford, CT: Appleton \& Lange.

[8] Duncan BB, Chor D, Aquino EM, Bensenor IM, Mill JG, Schmidt MI and Barreto SM. (2012). Chronic noncommunicable diseases in Brazil: priorities for disease management and research. Revista de saude publica, 46, 126-134.

[9] Wallace K. (2000). Determinants of health promoting behaviors in older adults.

[10] Fisher J. (2011). The four domains model: Connecting spirituality, health and well-being. Religions, 2(1), 17-28.

[11] US. Department of Health \& Human Seryices. (1990). Healthy people 2000. Washington, D.C.: U.S. Public Health Seryice.

[12] Schwarzer R and Knoll N. (2007). Functional roles of social support within the stress and coping process: A theoretical and empirical overview. International journal of psychology, 42(4), 243-252.

[13] Thoits PA. (2011). Mechanisms linking social ties and support to physical and mental health. Journal of health and social behavior, 52(2), 145-161.

[14] Grigorovich A, Lee A, Ross H, Woodend AK, Forde S and Cameron JI. (2017). A longitudinal view of factors that influence the emotional well-being of family caregivers to individuals with heart failure. Aging \& Mental Health, 21(8), 844-850.

[15] Dahlem NW, Zimet GD and Walker RR. (1991). The multidimensional scale of perceived social support: a confirmation study. Journal of Clinical Psychology, 47(6), 756-761.

[16] Walker SN, Sechrist KR and Pender NJ. (1995). Health promotion model-instruments to measure health promoting lifestyle: Health-promoting lifestyle profile [HPLP II](Adult version).

[17] Zaghden H, Kallel M, Elleuch B, Oudot J and Saliot A. (2007). Sources and distribution of aliphatic and polyaromatic hydrocarbons in sediments of Sfax, Tunisia, Mediterranean Sea. Marine Chemistry, 105(1), 70-89.

[18] Hogarh JNN, Seike YK and Masunaga S. (2012). Atmospheric polychlorinated naphthalenes in Ghana. Environmental Science and Technology, 46(5), 2600-2606.

[19] Juahir H. Spatial water quality assessment of Langat river basin (Malaysia) using environmetric techniques. Environmental Monitoring and Assessment, 2010. 173(1), 625-641.

[20] Azid A, Juahir H, Toriman ME, Kamarudin MKA, Saudi ASM, Hasnam CNC, Aziz NAA, Azaman F, Latif MT, Zainuddin SFM, Osman MR and Yamin M. (2014). Prediction of the level of air pollution using principal component analysis and artificial neural network techniques: A case study in Malaysia. Water, Air, and Soil Pollution, 225(8), 1-14.

[21] Wang WC, Chen KS, Chen SJ, Lin CC, Tsai JH, Lai CH and Wang SK. (2008). Characteristics and receptor modeling of atmospheric PM2. 5 at urban and rural sites in Pingtung, Taiwan. Aerosol and Air Quality Research, 8(2), 112129.

[22] Gazzaz NM, Yusoff MK, Ramli MF, Aris AZ and Juahir H. (2012). Characterization of spatial patterns in river water quality using chemometric pattern recognition techniques. Marine Pollution Bulletin, 64(4), 688-698.

\section{How to cite this article}

Norhilmi M. (2019). Predictors of health-promoting behaviour index among employees of different ages across adulthood. World Journal of Advanced Research and Reviews, 4(1), 01-05. 